www.jmscr.igmpublication.org

Index Copernicus Value: 79.54

ISSN (e)-2347-176x ISSN (p) 2455-0450

crossref DOI: https://dx.doi.org/10.18535/jmscr/v7i5.53

\title{
A Prospective study on fine needle aspiration cytology of clinically palpable breast lumps with histopathological correlation
}

\author{
Authors \\ Dr K.Vani ${ }^{1}$, Dr Chiguruvada Muni Ajitha ${ }^{2}$, Dr Amanulla Shaik ${ }^{3 *}$, Dr B. Hari Charan ${ }^{4}$, \\ Dr N. Prahalada Reddy ${ }^{5}$, Dr Ravi Theja Bathalapalli ${ }^{6}$, Dr K.Meghana ${ }^{7}$, \\ Dr G. Baswanth Kumar Reddy ${ }^{8}$ \\ ${ }^{1}$ Associate Professor of Surgery, Government Medical College (RIMS), Kadapa, India \\ ${ }^{3}$ Assistant Professor of Surgery, Government Medical College (RIMS), Kadapa, India \\ 2,4,5,6,7,8 Junior Resident of Surgery, Government Medical College (RIMS), Kadapa, India. \\ *Corresponding Author \\ Dr Amanulla Shaik \\ Assistant Professor of Surgery, Government Medical College (RIMS), Kadapa, India
}

\begin{abstract}
Breast cancer is the commonest malignancy in women worldwide and adequate preoperative evaluation is the most essential part of management of breast lumps. Management of breast lumps is challenging in resource poor settings. Although core needle biopsy has evolved as the diagnostic tool of choice for breast lumps, fine needle aspiration cytology (FNAC) still remains an important diagnostic tool as it is a quick, safe, cheap and reliable procedure that can be done bedside. With this background, we have conducted a prospective study to compare the diagnostic accuracy of FNAC in differentiating the benign and malignant lesions of palpable breast lump with histopathological correlation.

Conclusion: From our results, it can be advised that the patients in whom FNAC is unequivocally diagnostic for cancer can be managed directly by mastectomy or any other definitive therapy. We conclude that FNAC is a very important preliminary diagnostic test in palpable breast lumps, and if done by expert hands, the results show a high degree of correlation with the final histopathology report.

Key words: FNAC, Breast lump, Carcinoma of breast, Diagnosis.
\end{abstract}

\section{Introduction}

Diseases of the breast constitute a significant proportion of surgical cases seen in both developed and developing countries, and frequently the need arises to distinguish benign from malignant lesions prior to definitive treatment. The development in patient education and screening programmes have permitted a marked increase in the number of tumors detected ${ }^{1}$.
The most common sign and symptom of breast disease is a palpable mass; although breast diseases can also present as inflammatory lesion, nipple secretion or imaging abnormalities ${ }^{2}$. Most cases of breast lumps are benign but most of these patients are in a state of heightened anxiety until they have undergone specialist assessment, the necessary investigations and eventual reassurance $3.4,5$

Sometimes it is difficult to determine whether a 
suspicious lump is benign or malignant, simply from clinical examination. Therefore a method of definitive diagnosis of patients who present with breast lumps at the outpatient clinic is needed. This method must be accurate, easy to perform and reproducible. It must also be acceptable to the patient, can be carried out in a busy clinic setting and must not require too much preparation or expensive equipment.

Fine needle aspiration cytology (FNAC) of breast lump is an accepted and established method to determine the nature of the lump. It has been shown that FNAC can reduce the number of open breast biopsies ${ }^{6}$. FNAC is now used more frequently to diagnose any lump in the breast, which is clinically malignant. It is extremely beneficial in reaffirming the clinical impression of benign disease, which may not need subsequent biopsy. Furthermore, it allows more rapid diagnosis of a malignant condition in clinically non-suspicious masses. The ultimate benefit of aspiration cytology, however, rests in its demonstration of malignant disease, when other diagnostic modalities are inconclusive ${ }^{7}$. Fine needle aspiration cytology of the breast lumps is a substitute to excision biopsy in majority of instances and can differentiate and delineate the nature of the disease in most of the instances ${ }^{8}$.

Though critics have rightly pointed to the possibility of false negative reports in respect to malignant lesions, with improved techniques and expertise, a FNAC reported by an expert cytologist as unequivocally malignant is now considered by most, a sufficient evidence to proceed to definitive surgery 9 .

This study was undertaken to see how well a preliminary FNAC in a breast lump correlated with the final histopathology report to which every excised specimen would invariably be subjected. Since the needle aspiration cytology was done for palpable tumour, ultrasound guidance was not followed.

\section{Aims and Objectives}

Our study was conducted to compare the diagnostic accuracy of fine needle aspiration cytology in differentiating the benign and malignant lesions of palpable breast lump with histopathological correlation, to analyze the sensitivity, specificity, positive and negative predictive values and the efficacy of fine needle aspiration cytology.

\section{Materials and Methods}

Our study was a prospective study conducted on 200 female patients who attended the out-patient department of General Surgery in a tertiary care hospital in the Rayalaseema districts of Andhra Pradesh over a period of 1 year from August 2017 to July 2018.

\section{Inclusion Criteria}

1. Age between 10 and 70years.

2. Palpable breast lump of variable duration.

\section{Exclusion Criteria}

1. Patient with acute and tender breast lump like breast abscess.

2. Patient with ulcerated breast lump.

3. Recurrent breast lump of previously operated case of confirmed malignancy.

4. Patient is not willing for surgery.

5. Frank malignant mass with skin infiltration.

In out-patient department, a detailed history and thorough physical examination of the patient having palpable breast lump was carried out and entered in the proforma. The patient was informed about the procedure and informed consent was obtained from the patient before subjecting to fine needle aspiration cytology of the breast lump. FNAC of the breast lumps was done using standard techniques. The patients were informed about the cytological diagnosis. If the lumps on the cytological examination were reported as malignant, then mastectomy or modified radical mastectomy was performed and the specimen was sent for the histopathological confirmation of the diagnosis. Since the fine needle aspiration was done for palpable tumour, ultrasound guidance 


\section{JMSCR Vol||07||Issue||05||Page 321-327||May}

was not followed and repeat fine needle aspiration was carried out before open/excision biopsy if the pathologist report the cytology slide as "inadequate".

\section{Results}

Out of the 200 cases of FNAC done, 124 were diagnosed as benign lesions, 72 were diagnosed as malignant lesions and 4 cases were suspicious of malignancy.

Chart 1 - The results of FNAC.

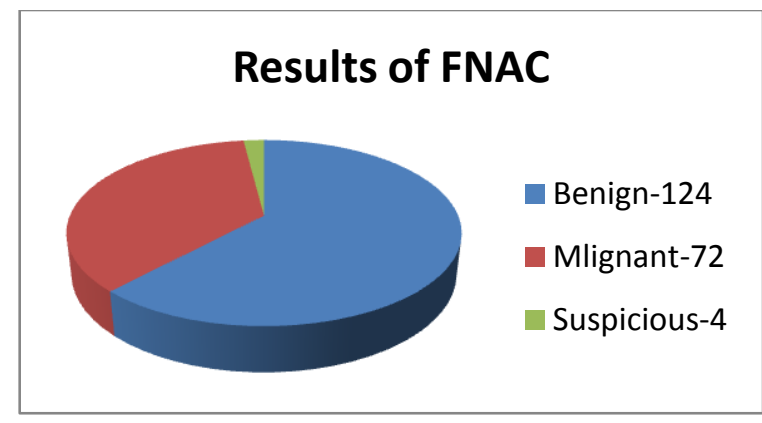

Of the 200 specimens that were sent for histopathological examination, 116 were diagnosed as benign lesions and 84 were diagnosed as malignant lesions.
Chart 2 The results of histopathology

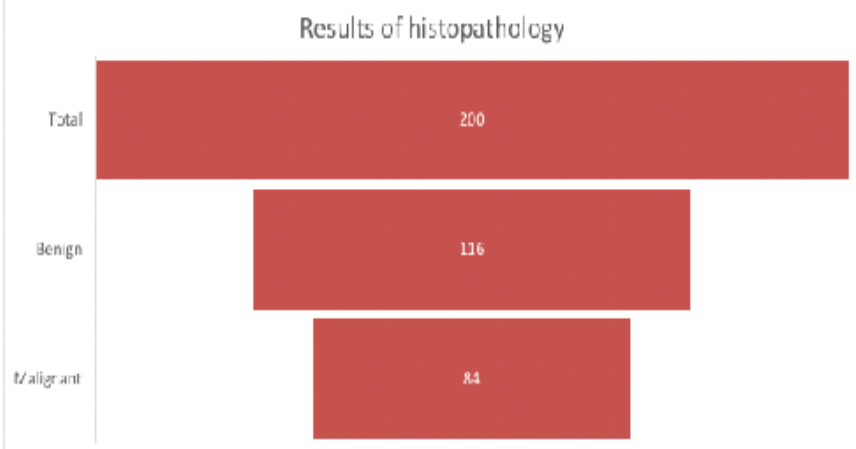

\section{Observations and results of benign lumps}

Of the 124 cases of benign lesions reported by fine needle aspiration cytology, 116 were confirmed by histopathology. False negative were 8 cases. False positive was zero. 8 cases were reported as unsatisfactory (inadequate) sampling, which on repeat fine needle aspiration cytology revealed benign fibroadenoma, later confirmed by histopathology after local excision.

The results of the benign lesions were as follows:

1. Accuracy rate for benign lesion $-100 \%$.

2. False positive $-0 \%$.

3. Unsatisfactory specimen rate $-6.45 \%$.

Chart- 3 The histopathological reports of benign breast lesions

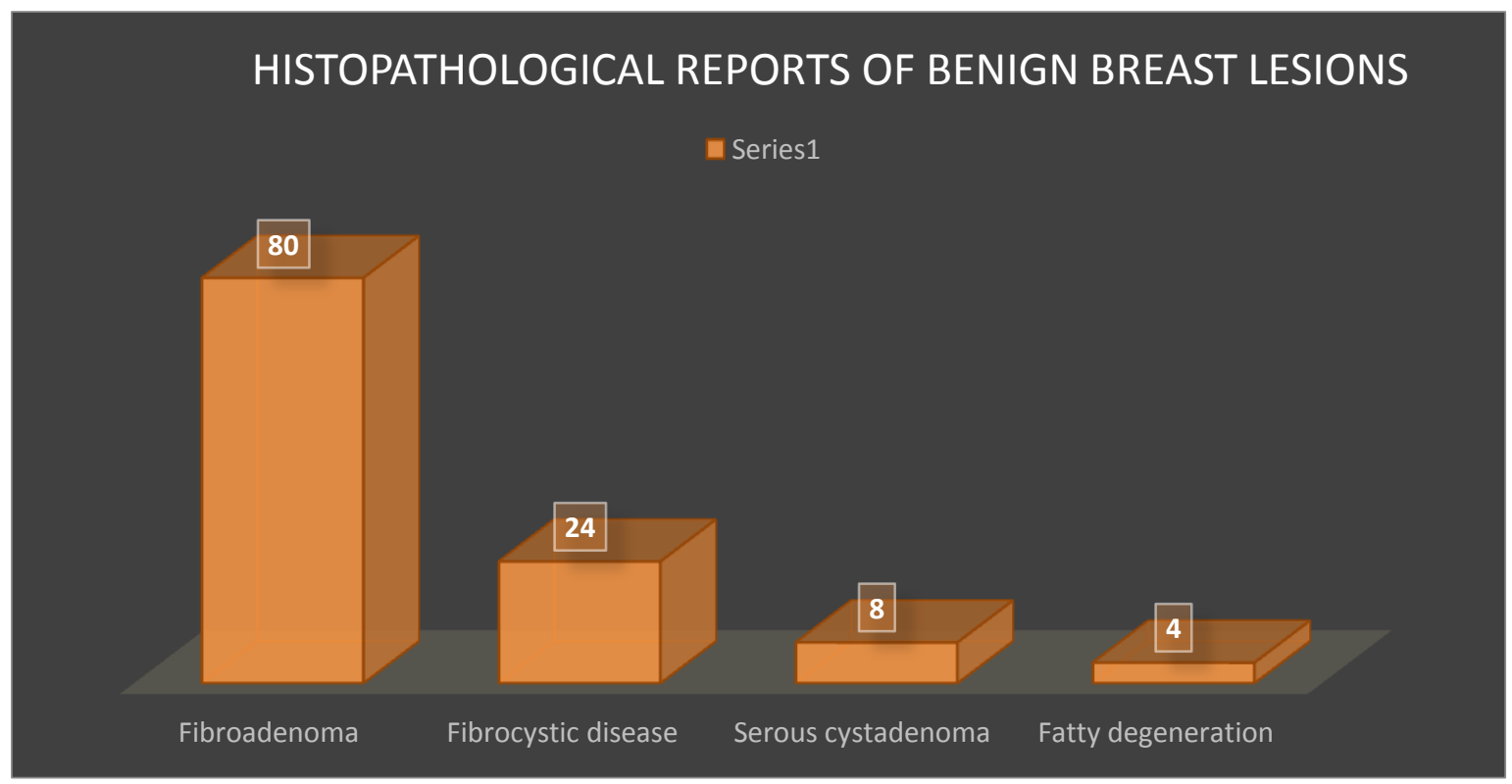


Observations and results of malignant lumps

Of the total 84 cases of malignant lesions, fine needle aspiration cytology reported 72 as malignant lesions, 8 as benign lesions and 4 as suspicious lesions. False negative were 8 and false positive was zero. Four cases on fine needle aspiration cytology were reported as suspicious lesions for malignancy. They underwent post operative rapid hematoxyline and eosine staining for confirmation of malignancy after surgical intervention and later histopathological confirmation. There was no unsatisfactory (inadequate) sampling for malignant lesions.

The results of the malignant breast lesions were as follows:

1. Accuracy rate for malignant lesion $-90 \%$.

2 . False negative rate $-10 \%$.

3 . Unsatisfactory specimen rate $-0 \%$.

Chart 4 The histopathological results of the malignant breast lesions

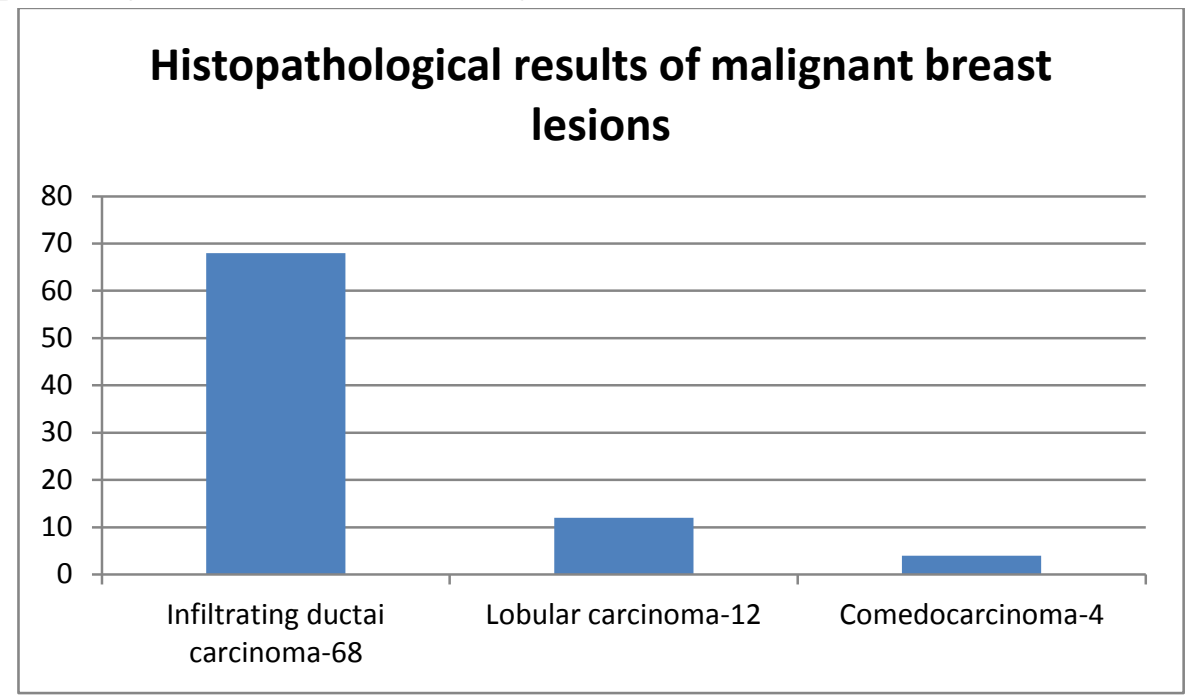

Among 8 cases of false negative, 4 cases were diagnosed as fibroadenoma depending on the presence of uniform cells in sheets with myoepithelial cells with minimal nuclear atypia on fine needle aspiration cytology. On local excision biopsy and histopathology they were confirmed as infiltrating ductal carcinoma. Later they underwent modified radical mastectomy in the same hospital stay.

In another 4 cases of breast lumps, which were diagnosed as benign proliferative breast disease with mild atypia by fine needle aspiration cytology, on local excision biopsy and histopathology they were confirmed as infiltrating ductal carcinoma. Later they underwent modified radical mastectomy.

We have found 4 suspicious cases in our study on FNAC, which on further histopathology was confirmed as malignant lesions. To calculate predictive value of the fine needle aspiration cytology of the palpable breast lump we excluded those 4 cases.

Table 1 The predictive value of the FNAC of the palpable breast lump

\begin{tabular}{cccc}
\hline $\begin{array}{l}\text { Test result } \\
\text { (FNAC) }\end{array}$ & $\begin{array}{l}\text { Disease } \\
\text { (malignant) }\end{array}$ & $\begin{array}{c}\text { Not diseased } \\
\text { (benign) }\end{array}$ & Total \\
\hline Positive & $72(\mathrm{a})$ & $0(\mathrm{~b})$ & 72 \\
Negative & $\begin{array}{c}\text { (True positive) } \\
8(\mathrm{c})\end{array}$ & $\begin{array}{c}\text { (False positive) } \\
116(\mathrm{~d})\end{array}$ & 124 \\
& (False negative) & (True negative) & \\
& & &
\end{tabular}

Total

80

116

196 
From the above observations, it is evident that the sensitivity of FNAC is $90 \%$ and its specificity is $100 \%$. The positive predictive value of FNAC is $100 \%$ and its negative predictive value is $93.55 \%$.

\section{Inadequate sampling (unsatisfactory report)}

Eight cases among the 200 fine needle aspiration cytology were reported as inadequate sampling (unsatisfactory) based on the presence of normal glandular cells on cytology. On repeat fine needle aspiration all the 8 cases were reported as fibroadenoma. Patients underwent local excision of the tumour and histopathological confirmation later. The inadequate sampling rate was $4 \%$.

\section{Discussion}

A lump in the breast is a common complaint presenting in the surgical out-patient department of all major hospitals, with anxiety regarding a possible malignancy being extremely common. Accurate diagnosis of cancer has been a diagnostic dilemma since long. A differential diagnosis of the benign, traumatic and malignant lesions is very essential in early stages of the disease. It is extremely important that unnecessary surgeries or invasive treatment for benign diseases are minimized and malignant lesions are managed aggressively in early stages.

Fine-needle aspiration cytology is widely used in the diagnosis of breast cancer because it is an excellent, safe, and cost-effective diagnostic procedure. One can get on site immediate report with minimal cost using inexpensive equipments and a simple technique. The most significant advantage of FNAC is the high degree of accuracy, rapid results, and a less invasive procedure than a tissue biopsy. FNAC of the breast can reduce the number of open breast biopsies $^{6,10,11,12}$.

In our study, which was conducted on 200 patients the commonest pathology which was found was fibroadenoma (80 in 200) which accounted for $40 \%$ of the cases. The observations are similar to study conducted by Sonali Saraf et al. who observed fibroadenoma as the commonest cause which was seen in 130 (40\%) of a total of 321 patients $^{13}$. Tiwari et al. also reported fibroadenoma as the commonest pathology $(39.6 \%)^{14}$.

In our study, where we had 84 malignant lesions, infiltrating ductal carcinoma was the most common malignant lesion that presented for needle aspiration. It forms $80.95 \%$ of the malignant lesions aspirated for cytology (68 out of total 84 cases). Singh A et al. reported that invasive ductal carcinoma is the commonest breast malignancy and found in the age group of 41-60 years of age ${ }^{15}$. Mital Chokshi et al. from Ahmedabad, Gujarat observed similar findings that the ductal carcinoma was the most common breast malignancy in the age group of 41-60 year of age ${ }^{16}$. Invasive ductal carcinoma in our study accounted for $34 \%$ of total fine needle aspirations. This is in contrast to a study by Tiwari et al who observed that invasive ductal carcinoma accounted for only $6.6 \%$ of the total 91 cases $^{14}$.

In our study, fine needle aspiration cytology revealed benign in 124 patients, suspicious in 4 and malignant in 72 patients with false negative results of 8 and false positive zero. The conditions which have a risk of a false positive result are papillary lesions, atypical epithelial hyperplasia, regenerating epithelial atypia and atypia of ductal epithelium in a cyst ${ }^{17}$. A risk of false negative results exists in low grade malignancies, small or complex proliferative lesions as well as in tumors with central necrosis or a small cell carcinoma.

To give a wider spectrum to our interpretation of the results, we calculated the specificity of FNAC as a diagnostic test for malignant lesions, i.e. how specific is FNAC a test in the diagnosis of malignancy in a breast lump. The positive predictive value of a test indicates the probability of a patient with a positive result to have the disease. Hence, it shows the diagnostic power of the test while the negative predictive value of a test, on the other hand, indicates the probability of a patient with negative result not to have the disease. 
The diagnostic accuracy of fine needle aspiration for benign lesions was $100 \%$ and malignant lesions were $90 \%$ with false negative rate of $10 \%$ and false positive rate of $0 \%$. The overall sensitivity of fine needle aspiration cytology in diagnosing the palpable breast lump in our study was $90 \%$, specificity was $100 \%$, positive predictive of $100 \%$ and negative predictive value of $93.55 \%$. Franco et al. in his study of 300 patients on the utility of FNAC, reported a positive predictive value of $100 \%$ and a negative predictive value of $92 \%^{18}$. A very large study of 1,297 patients done by Choi et al. on correlation of FNAC and histopathology reports, found the positive predictive value to be $98.4 \%$ and a negative predictive value of $88 \%{ }^{19}$. In a study conducted by Mulazim Hussain Bukhari et al, the sensitivity was $100 \%$, and the specificity was only 98\% because of false positives when compared with the histological reports ${ }^{20}$.

The unsatisfactory specimen rate as per our study was $6.45 \%$. In a study done by Mital Chokshi et al. $6.87 \%$ cases were unsatisfactory ${ }^{16}$. Unsatisfactory sample can be due to insufficient experience of the pathologist, radiologist or clinician who perform FNAC or due to nature of lesion itself. FNAC technique is as equally important as sample interpretation in reaching the correct diagnosis. Provision of adequate sample and experienced pathologist can prove FNAC as highly reliable diagnostic tool ${ }^{21}$.

The use of fine needle aspiration cytology as the main and direct indicator for mastectomy (without the needle for biopsy) remains controversial. The major concern is the danger of a false positive diagnosis, leading to unwarranted mastectomy. Since the false positive report is very rare (in our study it was zero), in the centers where the surgical staff is accustomed to performing mastectomy on the basis of fine needle aspiration cytology for diagnosis of cancer, there is necessary for a high level of confidence in and rapport with the cytopathologist.

\section{Conclusion}

The fine needle aspiration cytology is an important diagnostic tool in the management of patient with a breast lump. It is a patient friendly, quick, easy, reliable, repeatable and simple diagnostic test. When performed by expert hands, the diagnostic accuracy of FNAC is very high. A high sensitivity and a high positive predictive value proved that a positive FNAC in the breast means a definite diagnosis of the concerned pathology if compared with the final histology report. The high specificity and a high negative predictive value for malignancy illustrated the high accuracy of FNAC in the diagnosis of malignancy in the breast. It can be advised that the patients in whom fine needle aspiration cytology is unequivocally diagnostic for cancer can be managed directly by mastectomy or any other definitive therapy. Thus, we conclude that FNAC is a very important preliminary diagnostic test in palpable breast lumps, and if done by expert hands, the results show a high degree of correlation with the final histopathology report.

\section{References}

1. Mulford DK, Dawson AE. Atypia in fine needle aspiration cytology of non-palpable and palpable mammographically detected breast lesions. Acta Cytol 1994;38:9-17.

2. Klin TS and Neal HS. Role of needle aspiration biopsy in diagnosis of carcinoma of breast. Obstetrics and Gynecology 1975;46:89-92.

3. Cochrane RA, Singhal H, Monypenny IJ, Sebster DJ, Lyons K, Mansel RE. Evaluation of general practitioner referrals to a specialist breast clinic according to the UK national guidelines. Euro J Surg Oncol 1997; June 23(3):198-201.

4. Hughes JE, Royle GT, Buchanan R, Taylor I. Depression and social stress among patients with benign breast disease. $\mathrm{Br} \mathrm{J}$ Surg 1986;73:997-999.

5. Ellman R, Angel N, Moss S, Chamberlain J, Maguire P. Psychiatric morbidity associated 
with screening for breast cancer. Br J Cancer 1989;60:781-784.

6. Hindle WH, Payne PA, Pan EY. The use of fine needle aspiration in the evaluation of persistent palpable dominant breast masses. Am J Obstetrics Gynaecol 1993; 168 (6 Part 1):1814-8.

7. Russ JE, Winchester DP, Scanlon EF, Christ MA. Cytologic findings of aspiration of tumours of the breast. Surg. Gynecol Obstetric 1978; 146:407-411.

8. Khajuria R, Goswami KC, Singh K, Dubey VK. Pattern of Lymphadenopathy on Fine Needle Aspiration Cytology in Jammu. JK Science, 2006;8(3).

9. A. Khemka, N. Chakrabarti, S. Shah, V. Patel. Palpable Breast Lumps; Fine-Needle Aspiration Cytology versus Histopathology: a Correlation of Diagnostic Accuracy. The Internet Journal of Surgery. 2009 Volume 18 Number.

10. H. C. Lee, P. J. Ooi, W. T. Poh, and C. Y. Wong, "Impact of inadequate fine-needle aspiration cytology on outcome of patients with palpable breast lesions," Australian and New Zealand Journal of Surgery, vol. 70, no. 9, pp. 656-659, 2000.

11. H. Khatun, N. Tareak-Al-Nasir, S. Enam, M. Hussain, and M. Begum, "Correlation of fine needle aspiration cytology and its histopathology in diagnosis in breast lumpus," Bangladesh Medical Research Council Bulletin, vol. 28, no. 2, pp. 77-81, 2002.

12. Q. He, X. Fan, T. Yuan et al., "Eleven years of experience reveals that fine-needle aspiration cytology is still a useful method for preoperative diagnosis of breast carcinoma," Breast, vol. 16, no. 3, pp. 303306, 2007.

13. Sonali Saraf, Manisha Khare, Alka Kalgutkar Fine Needle Aspiration Cytology of Breast Lumps- A correlation with histopathology diagnosis, Indian Journal of Pathology and Oncology, January - March 2016;3(1);103-106.
14. Tiwari M. Role of fine needle aspiration cytology in diagnosis of breast lumps.

Kathmandu University Medical Journal (2007), Vol. 5, No. 2, Issue 18, 215-217.

15. Singh A, Haritwal A, Murali BM. Pattern of breast lumps and diagnostic accuracy of Fine needle aspiration cytology; A hospital based study from Pondicherry, India. The internet journal of pathology 2011;11(2).

16. Mital Chokshi, Nandita Mehta cytological study of palpable breast lumps (407 cases) with their histological correlation International Journal of Medical Science and Public Health | 2014 | Vol 3 | Issue 2.

17. A Khemka, N Chakrabarti, S Shah, V Patel. Palpable Breast Lumps: Fine-Needle Aspiration Cytology versus Histopathology: a Correlation of Diagnostic Accuracy. The Internet Journal of Surgery. 2008 Volume 18 Number 1.

18. Medina Franco H, Abara Perez L. Fine needle aspiration biopsy - institutional experience. Zubiran 2005;57:394- 8.(s)

19. Choi YD, Choi YH, Lee JH, Nam JH, Juhng SW, Choi C. ActaCytol. 2004;48:801-6.

20. Mulazim Hussain Bukhari, Madiha Arshad, Shahid Jamal, Shahida Niazi, Shahid Bashir, Irfan M. Bakhshi, and Shaharyar Use of Fine-Needle Aspiration in the Evaluation of Breast Lumps, Pathology Research International Volume 2011, Article ID 689521, 10 pages doi:10.4061/2011/689521 ]

21. Koss LG, Melamed MR. Koss' Diagnostic Cytology and Its Histopathologic Bases. 5th ed. Philadelphia: Lippincott Williams \& Wilkins. 2006. pp. 1081-84. 